\title{
Capsule Commentary on Ancker et al., Rapid Growth in Use of Personal Health Records in New York, 2012-2013
}

\author{
Holly O. Witteman, PhD \\ Department of Family and Emergency Medicine, Office of Education and Continuing Professional Development, Research Center of the \\ CHU de Québec, Laval University, Quebec City, Quebec, Canada.
}

J Gen Intern Med 29(6):893

DOI: $10.1007 / \mathrm{s} 11606-014-2822-0$

() Society of General Internal Medicine 2014

$\mathrm{T}$ his study by Ancker and colleagues ${ }^{1}$ reports findings from two recent consecutive years of random-digit dial public surveys in the state of New York. Within a longer survey, respondents answered four questions about their use of a personal health record or patient portal (grouped together under the term personal health records) in the past year. This study provides insight as to how the meaningful use program and other forces might be encouraging implementation of electronic health records. The proportion of people reporting having used a personal health record increased over the 1-year time period: from 11 to $17 \%$.

This represents a notable increase; however, the overall proportion remains small. Moreover, usage was lower among certain groups, for example, people with less education or who did not use the Internet or email daily. These findings are in line with what is already known about the digital divide, and highlight the importance of paying particular attention to the needs of more vulnerable populations in the implementation of personal health records ${ }^{2}$ in order to ensure that these tools are useful to and usable by the people who stand to benefit most from them. ${ }^{3}$

More broadly, further research is needed to understand the contextual details of the design, development and implementation of personal health records, especially as they are used in diverse settings and with different design features. For example, although both serve valuable purposes, a personal health record that supports and encourages communication between rural patients and health care providers is fundamentally different from one that enables patients at an academic medical center to log in and view their laboratory results.
In this vein, when evaluating, designing or choosing an electronic health record, it is important to consider whose goals the system is designed to meet. The technology should be adapted to the people who use it, rather than expecting people to adapt to the technology. Such an approach is grounded in human factors, a field that is making contributions in the area of patient safety, ${ }^{4}$ and that could also play a larger role in the area of health information technology. ${ }^{5}$

Conflict of Interest: The author declares that she does not have a conflict of interest.

Corresponding Author: Holly O. Witteman, PhD; Department of Family and Emergency Medicine, Office of Education and Continuing Professional Development, Research Center of the CHU de Guébec, Laval University, Quebec City, Quebec G1V OA6, Canada (e-mail: holly.witteman@fmed.ulaval.ca).

\section{REFERENCES}

1. Ancker JS, Silver M, Kaushal R. Rapid growth in use of personal health records in New York, 2012-2013. J Gen Intern Med. 2014. doi:10.1007/ s11606-014-2792-2.

2. Sarkar U, Karter AJ, Liu JY, Adler NE, Nguyen R, López A, et al. Social disparities in internet patient portal use in diabetes: evidence that the digital divide extends beyond access. J Am Med Inform Assoc. 2011;18(3):318-1.

3. Kruse RL, Koopman RJ, Wakefield BJ, Wakefield DS, Keplinger LE, Canfield SM, et al. Internet use by primary care patients: where is the digital divide? Fam Med. 2012;44(5):342-7.

4. Gurses AP, Ozok AA, Pronovost PJ. Time to accelerate integration of human factors and ergonomics in patient safety. BMJ Qual Saf. 2011;30:1-6.

5. Elkin PL. Human factors engineering in HI: So what? Who cares? and What's in it for you? Health Inf Res. 2012;18(4):237. 